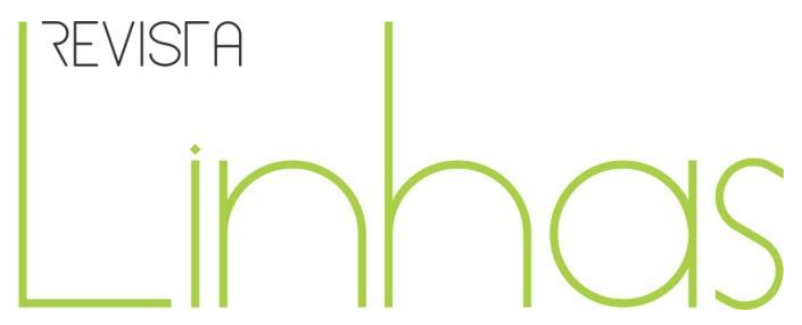

\title{
O ensino de ciências da natureza na escola única do trabalho na obra de Pistrak (1888-1937): notas introdutórias sobre a educação soviética no início do século XX
}

\begin{abstract}
Resumo
O objetivo do presente artigo é analisar a experiência de Pistrak na escola única do trabalho, instituição Escola Lepechinski (Moscou, Rússia), no contexto da Revolução Bolchevique de 1917, buscando uma análise crítica de seu conteúdo no que tange à área de ciências da natureza. O estudo lança mão de uma pesquisa documental, realizada por meio do estudo das principais obras traduzidas para o português do pedagogo socialista, bem como de uma pesquisa bibliográfica como método acessório. Os resultados da pesquisa sobre os documentos analisados e a literatura investigada indicaram o uso de algumas metodologias para as atividades pedagógica, como pesquisa empírica, experimentação, demonstrações, leitura de livros, excursões e palestras. Ademais, descreve-se que os pedagogos da referida escola utilizavam o ensino por complexos, edificando uma teoria pedagógica com base na articulação entre trabalho e educação. No que tange aos aspectos curriculares de temas ensinados na escola, destaca-se o ensino de botânica, biologia geral, química, física e o estudo zoológico, o qual incluía uma visão em ordem crescente de desenvolvimento biológico. Por fim, analisa-se os temas do ensino do corpo e humano e educação sexual, com foco numa visão ampla e dialética desses temas.
\end{abstract}

Palavras-chave: Pedagogia russa. Ensino de ciências. Educação crítica.

\author{
Raphael Alves Feitosa \\ Universidade Federal do Ceará - \\ UFC - Fortaleza/CE \\ raphael.feitosa@ufc.br
}

\footnotetext{
Para citar este artigo:

FEITOSA, Raphael Alves. O ensino de ciências da natureza na escola única do trabalho na obra de Pistrak (1888-1937): notas introdutórias sobre a educação soviética no início do século XX. Revista Linhas. Florianópolis, v. 22, n. 48, p. 221-247, jan./abr. 2021.
} 


\title{
Natural sciences education in the single school of labor in the Pistrak's (1888-1937) biography: introductory notes on Soviet education in the early 2oth Century
}

\begin{abstract}
The objective of this paper is to analyze Pistrak's experience at the unique school of labor, institution Lepechinski School (Moscow, Russia), in the context of the Bolshevik revolution of 1917, seeking a critical analysis of its content in the area of natural sciences. The study uses documentary research, carried out by studying the main works translated into Portuguese by the socialist pedagogue, as well as bibliographic research as an accessory method. The results of the research under the analyzed documents and the investigated literature indicated the use of some methodologies for pedagogical activities, such as the use of empirical research, experimentation, demonstrations, reading books, excursions and lectures. Furthermore, it is described that the pedagogues of that school used teaching by complexes, building a pedagogical theory based on the articulation between work and education. Regarding the curricular aspects of themes taught at school, the teaching of botany, general biology, chemistry, physics and zoological study stands out, which included a view in an increasing order of biological development. Finally, the themes of body and human education and sexuality education are analyzed, focusing on a broad and dialectical view of these themes.
\end{abstract}

Keywords: Russian pedagogy. Science teaching. Critical education. 


\section{Introdução}

O campo do ensino de ciências vem sendo debatido e criticado no Brasil, desde suas concepções curriculares, passando pelas abordagens filosóficas de suas práticas de ensino e formação docente. Contudo, ainda são escassas as pesquisas que denotem uma abordagem crítica desse campo específico e de temas correlatos (educação ambiental, educação sexual, entre outros); em especial, detecta-se carência de estudos vinculados a um viés materialista e histórico (CUNHA; SILVA, 2016; FEITOSA; LEITE, 2014; LOPES, 2018; NUNES, 2016). Em adição, Sheehan (1985) indicou que essa lacuna também é sentida em outros países, como naqueles da América Anglo-saxônica.

Diante desse contexto acadêmico, a propositura argumentativa trazida no presente manuscrito necessita como fundamento primeiro, reconhecer o mundo humano como um mundo incessantemente mutável e dialeticamente relacional ao longo de sua história. Assim sendo, torna-se relevante refletir sobre as possibilidades de uma educação que inclua o trabalho como elemento primordial, através de investigações que abordem o período revolucionário russo, após a Revolução Bolchevique de 1917.

Nesse ensejo revolucionário, vários pedagogos soviéticos como Nadjla Krupskaia, Moisey Pistrak, Anton Makarenko e Viktor Shulgin desenvolveram uma proposta pedagógica que vai ao encontro do movimento socialista que se erguia na Rússia (AMBONI; BEZERRA NETO; BEZERRA, 2013; GOLOVATY, 2017a, 2017b; LUCENA et al., 2011; PERGHER; FRIZZO, 2018). Nessa perspectiva, uma experiência educativa soviética que vem sendo fonte referencial para análises sobre a articulação entre educação, ciência e sociedade, através do trabalho como princípio educativo, é a práxis da Escola Lepechinski (Moscou, Rússia), chamada de escola única do trabalho ou escola-comuna, a qual lidava com crianças e jovens. Isso exposto, indaga-se: como se deu o ensino da área de ciências da natureza durante a experiência soviética da escola-comuna?

Desta feita, o objetivo da presente investigação é analisar a experiência pistrakiana na escola única do trabalho, no contexto da revolução bolchevique, buscando uma análise crítica de seu conteúdo no que tange à área de ciências da natureza.

As pesquisas em torno dos trabalhos de Pistrak são escassas no Brasil, mas os estudos de suas práticas educativas vêm florescendo em nosso país e justificam o 
interesse pela análise crítica de seus trabalhos, além de verificar suas possíveis contribuições para a escola contemporânea (BARROSO et al., 2020; BOLEIZ JÚNIOR, 2017; SACHS; CORRÊA, 2020). Contudo, destaca-se a exígua literatura produzida em língua portuguesa sobre a biografia pistrakiana, bem como de outros autores marxistas, em especial no que diz respeito ao campo do ensino de ciências (CONDE; COSTA, 2019; FEITOSA; LEITE, 2014; SACHS; CORRÊA, 2020; SOARES DOS SANTOS; PALUDO, 2016).

Com relação ao procedimento metodológico, o presente estudo lança mão de uma pesquisa documental, realizada por meio do estudo das principais obras traduzidas para o português do pedagogo socialista Moisey M. Pistrak (2009, 2015, 2018). A investigação documental, nos moldes indicados por Creswell (2010), foi fundamental para ampliar a compreensão sobre o tema aqui analisado, indicando elementos para a contextualização histórica e sociocultural da biografia pistrakiana. Os documentos obtidos e analisados funcionam como fonte de informação significativa e são apresentados excertos dos textos de Pistrak como evidências, os quais acrescentaram uma dimensão histórica à compreensão social da educação soviética no período supra indicado.

Outrossim, também foi feita uma pesquisa bibliográfica como método acessório. Esse tipo de pesquisa se vincula às de caráter qualitativo, feita através de investigação em portal de pesquisa e base de referência de dados acadêmicos (foi utilizado o Portal de Periódicos CAPES - www.periodicos.capes.gov.br), num esforço para descobrir o que já foi produzido cientificamente sobre a biografia de Pistrak e seus temas correlatos, como a escola do trabalho e a pedagogia russa. A investigação bibliográfica, feita seguindo as proposições de Bogdan e Biklen (1994), teve relevância fundamental, pois impulsionou o aprendizado do tema, bem como permitiu catalogar e sistematizar as publicações da área. A partir dessa ferramenta metodológica, foram elencados na pesquisa vários trabalhos ligados a biografia pistrakiana (AMBONI; BEZERRA NETO; BEZERRA, 2013; BARROSO et al., 2020; BOLEIZ JÚNIOR, 2017; CUNHA; SILVA, 2016; GOLOVATY, 2017a, 2017b; LUCENA et al., 2011; SACHS; CORRÊA, 2020; SOARES DOS SANTOS; PALUDO; 2016; PERGHER; FRIZZO, 2018; VALLE, 2012; VALLE; ARRIADA, 2014).

Desta feita, a presente investigação será exposta em duas partes que se articulam. De início, são tecidas considerações a respeito da biografia pistrakiana e de seu contexto 
histórico, com o intuito de evitar anacronismos, obtido através de investigações publicadas em língua portuguesa, fruto da pesquisa bibliográfica desenvolvida. Em seguida, apresenta-se uma breve exposição e são feitas reflexões sobre o ensino da área de ciências da natureza na escola única do trabalho, a partir das obras de Pistrak (2009, 2015, 2018), buscando uma introdução à análise crítica de sua práxis.

\section{Biografia pistrakiana e seu contexto histórico em algumas investigações publicadas em língua portuguesa}

Moisey Mikhailovich Pistrak nasceu em 1888 na cidade de Kamianets-Podilskyi (Ucrânia), sendo preso e assassinado em Moscou (Rússia) no ano de 1937. Não há grandes informações sobre sua trajetória política e intelectual (PERGHER; FRIZZO, 2018), embora se saiba que esse educador soviético se formou em Físico-Matemática em 1914 e era doutor em Ciências Pedagógicas (GOLOVATY, 2017a, 2017b). Ele ingressou nos quadros do Comissariado Nacional de Educação (NarKomPros) nos idos de 1918, período em que trabalhou na Escola Experimental-Demonstrativa Lepechinskiy, conhecida como comuna escolar (BARROSO et al., 2020).

Em 1925, Pistrak publicou a obra "Fundamentos da escola do trabalho". Outros dados bibliográficos trazidos por Amboni, Bezerra Neto e Bezerra (2013), e por Boleiz Júnior (2017), indicam que o pensador socialista atuou no Instituto de Pedagogia do Norte do Cáucaso em 1931. Já no ano de 1936, o pedagogo soviético foi diretor do Instituto Central de Pesquisa Científica de Pedagogia, ligado ao Instituto Superior Comunista de Educação, e era tido como membro da classe intelectual da intelligentsia bolchevique.

O educador revolucionário escreveu suas obras considerando o seu trabalho pedagógico na Escola Lepechinsky (Moscou, Rússia) e sua militância comunista no princípio do século XX no território russo e, em ato contínuo, na União Soviética (SOARES DOS SANTOS; PALUDO, 2016; VALLE; ARRIADA, 2012). Devido ao fato de as obras pistrakianas terem tido pouca divulgação no período Stalinista da sociedade soviética, existem lacunas sobre sua biografia (LUCENA et al., 2011; PERGHER; FRIZZO, 2018). 
Apesar dessas lacunas históricas, os textos associados a Pistrak descreveram com propriedade as experiências educativas durante o período russo pós-revolucionário (BOLEIZ JÚNIOR, 2017). Seu foco, e de seus colegas pedagogos, era educar o Homo novus comunista, aquele que iria viver na emergente sociedade socialista.

Com relação a publicações de língua portuguesa sobre o autor, vários pesquisadores brasileiros vêm se dedicando ao estudo de sua biografia, sobretudo, na segunda década do atual século. Por exemplo, Valle (2012) investigou a contribuição de Pistrak na Escola Lepechinski, em Moscou (Rússia) e de Makarenko na Colônia Gorki, em Poltava e Khárkov (Ucrânia), no período que se seguiu à Revolução de 1917. A autora expôs que Pistrak demonstrou que a questão pedagógica mor é a definição das finalidades da educação, e não exatamente o método educativo, ou os saberes curriculares a serem ensinados.

Valle e Arriada (2012) analisaram alguns aspectos comuns da pedagogia de Anton Semiónovitch Makarenko e Moisey Pistrak. Os resultados da pesquisa apontam que esses pedagogos soviéticos possuem sinergia no que diz respeito ao uso do labor como princípio educativo, através dos princípios da auto-organização, coletividade e trabalho produtivo.

Amboni, Bezerra Neto e Bezerra (2013) também se dedicaram a obra pistrakiana, mostrando que em sua obra e na de outros pedagogos russos (como Krupskaia, Lunatcharski, Makarenko etc.), a organização da vida escolar está vinculada ao trabalho produtivo e à formação dos valores do homem comunista.

As contribuições de Pistrak e de sua pedagogia socialista para experiências Pedagogia do Movimento dos Trabalhadores Sem Terra (MST) foi tema de investigação por parte de Santos e Paludo (2016). Os resultados de tal pesquisa indicaram a possibilidade de construção de uma pedagogia cuja categoria central passa a ser o trabalho, pautada nos princípios da educação comunista.

Outrossim, a relevância da obra do pedagogo soviético no período que sucede a Revolução de 1917, na qual a sociedade russa se viu às voltas com a necessidade de reformar sua rede de Educação, foi analisado por Boleiz Júnior (2017). O trabalho mostrou que o objetivo dessa reformulação foi adequar a escola aos ideais comunistas. Nesse 
contexto, a escola Lepechinski, destaque da obra pistrakiana, ganhou notoriedade por trazer na prática o trabalho como princípio fundamental, no qual se busca uma educação para o proletariado, rumo à edificação de uma sociedade sem classes.

Os estudos de Golovaty (2017a, 2017b) também trouxeram a obra de Pistrak, apresentando uma reflexão sobre a concepção de escola politécnica do trabalho. A partir da luta de classes e dos processos de burocratização na sociedade russa entre 1917-1929, a escola politécnica soviética caiu nas armadilhas do processo de burocratização. Golovaty destacou algumas contradições da proposta de Pistrak, como, por exemplo, a defesa do leninismo e da eliminação progressiva do Estado, cuja escola possui papel fundamental na educação das massas, permitiu o fortalecimento da burocracia estatal e do capitalismo de Estado (GOLOVATY, 2017a). Ademais, a falta de sintonia entre a ideia pistrakiana de politecnia e as diretrizes da Nova Política Econômica russa, sendo que essa última acabou por diluir a radicalidade da proposta do pedagogo soviético (GOLOVATY, 2017b).

Outros pesquisadores que investigaram os escritos de Pistrak foram Pergher e Frizzo (2018). Com foco na categoria de trabalho como princípio educativo, esses autores debateram as contribuições de Antônio Gramsci e Moisey Pistrak para o tema da educação crítica. Através de uma análise materialista e dialética, esses pesquisadores elencaram algumas experiências da Escola do Trabalho Soviética, a qual mirava uma educação de e para os trabalhadores.

Quaresma (2018) mostrou que Pistrak foi um educador-militante importante no que diz respeito a uma pedagogia construída na relação trabalho-educação. O resultado da pesquisa dessa autora apontou que a biografia pistrakiana, dentro da escola comuna, vem sendo referência atual para o desenvolvimento de práxis educativas vinculadas às categorias de autogestão e coletivismo.

Conde e Costa (2019) refletiram sobre a Pedagogia Socialista, incluindo a literatura pistrakiana, para a concepção de educação infantil do Movimento dos Trabalhadores Rurais Sem Terra (MST). Seus resultados indicaram que o grupo entendeu a criança e a sua educação como fruto de relações sociais edificadas historicamente.

Há pouco tempo, a biografia do educador soviético foi fruto de investigação por Barroso et al. (2020), na qual os autores refletiram sobre os subsídios fornecidos por 
Pistrak no movimento intitulado Pedagogia Russa, entre os anos de 1917 e 1932. Tal pesquisa observou que a pedagogia pistrakiana na escola única do trabalho soviética ambicionava uma formação humana capaz de edificar uma nova sociedade sem classes.

Já no campo empírico de experiências educativas brasileiras, Sachs e Corrêa (2020) investigaram uma proposta pedagógica baseada na Pedagogia Russa com estudantes de Ensino Fundamental de uma escola do campo em área de Reforma Agrária (Londrina, Paraná, Brasil). As autoras destacaram que a práxis escolar com base na visão pistrakiana do ensino por complexos gerou uma maior conexão com a realidade dos alunos. Além disso, permitiu a discussão de temas da atualidade, articulação com outros saberes dos alunos e a utilização do inventário da realidade.

Como pode ser visto na revisão de literatura exposta nos parágrafos anteriores, Pistrak vem recebendo atenção de vários pesquisadores. Nada obstante, há pouca menção sobre o tema específico do ensino de ciências ministrado na escola-comuna moscovita. E é exatamente sobre isso que se dedica, de maneira breve, a seguir, alguns pontos introdutórios acerca do ensino de ciências da natureza na instituição Lepeshinskiy.

\section{Notas introdutórias sobre o ensino de ciências da natureza na escola Lepeshinskiy}

Antes de adentrar no campo específico do ensino de ciências da natureza, é necessário destacar alguns pontos sobre as finalidades e organização da escola Lepeshinskiy. De início, é relevante denotar que a nova escola socialista deveria ser a formadora do novo ser comunista, uma espécie de Homo novus, voltado a um novo tempo histórico de se iniciava. Segundo o levantamento documental, Pistrak (2009, 2015, 2018) afirmava que esse novo tempo repleto de transformações em prol da sociedade comunista necessitava uma teoria revolucionária que a sustentasse.

Nesse sentido, Barroso et al. (2020), Golovaty (2017a, 2017b) e Quaresma (2018) mostraram que Pistrak tinha um claro referimento à frase do pensamento crítico-dialético leniniano, a saber: sem teoria revolucionária não pode haver movimento revolucionário. Entre os documentos analisados na presente investigação, Pistrak (2018, p. 32) explicitou 
tal visão ao afirmar que “[...] sem teoria pedagógica revolucionária, não poderá haver prática pedagógica revolucionária”.

Do ponto de vista de Pistrak, as instituições escolares são uma arma ideológica para o proletariado revolucionário (BOLEIZ JÚNIOR, 2017; PERGHER; FRIZZO, 2018). Assim, além da força física e militante que as massas trabalhadoras inerentemente possuem, é necessário, em adição, uma educação mais sistematizada de quem são e do que precisam, direcionando as forças para os ideais revolucionários. Na nova escola advinda desse contexto, seriam ensinadas as várias maneiras dos aprendizes pensarem e agirem em função dos interesses coletivos das massas trabalhadoras, visando a consolidação do socialismo, projetando uma sociedade sem classes.

Seguindo a filosofia da revolução bolchevique, a teoria pedagógica da escola do trabalho seguia pelo viés do marxismo, aderindo ao materialismo histórico e dialético. Explicitamente, em um de seus documentos, Pistrak (2018, p. 33, grifo do autor) enfatizou que "[...] a teoria marxista deve ser assimilada como um instrumento ativo de transformação da escola, e é necessário fazer uso rigoroso dela no trabalho escolar". Assim, a categoria trabalho ocupou um grande espaço na obra pistrakiana (QUARESMA, 2018; VALLE, 2012; VALLE; ARRIADA, 2014). Pistrak denotava o caráter formativo do trabalho e da educação como ação humanizadora por meio do desenvolvimento de todas as potencialidades do ser humano. Inclusive, o surgimento do nome popular pelo qual ficou conhecida a escola Lepeshinskiy, a escola-comuna, vem de tal categoria. "A essa época também se relaciona o aparecimento do nome da nossa escola: 'comuna escolar' nome dado pelas próprias crianças" (PISTRAK, 2009, p. 147).

O pedagogo descreveu o surgimento desse nome, em fato ocorrido após a abertura do internato da escola de Moscou. Para seu funcionamento, foi necessária não apenas a produção coletiva de café da manhã, mas também de almoço e jantar. Foi exatamente durante o preparo de uma dessas refeições, quando as crianças preparavam para si o seu primeiro almoço comunal, sentadas ao redor da mesa, “[...] um dos meninos salta no banco e grita: 'Irmãos, nós já temos uma comuna!' - 'Sim, sim' - gritaram os demais. Alguém começou a aplaudir e o resto apoiou" (PISTRAK, 2009, p. 147). Daí em diante, os jovens passaram a discutir sobre o motivo de que muitos russos ainda terem 
medo do comunismo, se para eles a comuna era algo positivo. Desde esse momento, os integrantes da instituição começaram a chamá-la de comuna escolar.

Na escola-comuna de Lepeshinskiy, Pistrak (2009, 2015, 2018) apresentou algumas formas de trabalho comunal que eram desenvolvidos na instituição de ensino, distribuídas de acordo com a faixa etária dos jovens. As diversas atividades - os trabalhos domésticos, trabalhos sociais produtivos - serviriam para a formação de valores, do espírito de coletividade, similar a uma vida social ativa. Nas palavras do próprio pedagogo, a questão do trabalho na escola é a base da educação e "[...] deve ser colocada em ligação com o trabalho social, com a produção real, com a atividade concreta socialmente útil [...]" (PISTRAK, 2018, p. 49). O estudo sistemático desse trabalho era a base dos novos programas escolares implementados.

No tocante à organização dos grupos escolares, a comuna escolar moscovita possuía sistema escolar dividido em $1^{\circ}$ e $2^{\circ}$ graus, sendo o $1^{\circ}$ composto por dois grupos (I e II, cujos alunos eram divididos de acordo com a faixa etária, ficando os mais noviços no grupo I) e o $2^{\circ}$ também formado por dois grupos (III e IV). O ensino nessa escola não objetivava servir apenas como preparatório para uma universidade, e sim projetar uma formação geral e preparação para o mundo produtivo (PISTRAK, 2009, 2015, 2018).

A respeito do enfoque marxista da organização do trabalho como princípio educativo, Pistrak (2018) mostra que esse fundamento deve ser a base da escola, consequentemente, também para suas disciplinas.

As Ciências da Natureza, Física e Química entrarão na escola com nova interpretação e com novas tarefas, isto é, tornando claros os fenômenos da natureza, principalmente com o ponto de vista de seu uso pelas pessoas na produção. A antiga concepção contemplativa da natureza deve ser afastada. (PISTRAK, 2018, p. 44)

Nos documentos produzidos por Pistrak (2009, 2018), encontram-se relatos de experiências pedagógicas interessantes que retratam como era o ensino de ciências da natureza e sua ligação com o trabalho como princípio educativo. De acordo com o educador soviético, o ensino da área tinha ligação com as tarefas práticas da sociedade, sendo uma delas a produção de alimentos. A escola comunal tinha sua própria horta experimental, na qual era executada uma série de experimentos e conduzia-se o trabalho 
no laboratório da escola, além da produção agrícola de vários vegetais. Isso ocorria sob a mediação do pedagogo de ciências naturais.

Outro exemplo que se vincula ao tema, eram as aulas de exploração de campo (chamadas de excursões). Na biografia pistrakiana tem-se relato de uma dessas empreitadas à estação elétrica Shatur (Moscou, Rússia). Com o pedagogo de ciências naturais e de ciências sociais, além de técnicos da própria estação, nessa aula de campo foi feita a análise do solo, da vegetação e também foi trabalhada o tema da turfa. “Colocou-se a questão sobre o papel da turfa na construção econômica da Rússia, e esta questão aprofundou-se e transformou-se na questão sobre a construção da Rússia no momento presente" (PISTRAK, 2009, p. 158). Note-se no trecho a relação entre o conhecimento científico, trabalho e sociedade, no contexto russo das décadas de 1910-20. Essa articulação entre o saber científico e diversos campos do conhecimento é potencializada por uma relação dialética e histórica do conhecimento de ciências da natureza (FEITOSA; LEITE, 2014).

O trabalho educativo na horta comunal era mote gerador de saberes para a juventude campesina. Nos documentos pesquisados, Pistrak $(2009,2015)$ revela que um dos objetivos de sua pedagogia era permitir que o jovem pudesse estudar o lado revolucionário das tarefas no campo da economia rural, educando os adolescentes nas relações sociais, não os separando do solo camponês natal. Assim, ao terminar seu percurso na escola, devolviam-se os jovens para suas comunidades com novos hábitos comunais e pontos de vista coletivistas. "Ao mesmo tempo, construir uma economia doméstica experimental, desenvolver o trabalho social entre os camponeses, tentar tornar-se um centro cultural da região" (PISTRAK, 2009, p. 168-169).

Além da horta escolar, outros elementos laborais eram incorporados à escolacomuna. Exemplificando, tinham-se oficinas escolares, tidas como forma de fazer com que o jovem compreendesse a essência da divisão trabalhista e uma mecanização de produção com ênfase em objetos de interesse social e da própria escola. Outrossim, havia o estudo da fábrica, realizado em parceria com indústrias e manufaturas da comunidade do entorno da escola. Nesse espaço se desenvolvia o trabalho escolar, com o intuito de compreender os sistemas produtivos e suas relações sociais e políticas. Os chamados trabalhos improdutivos também tinham espaço na escola, sem a produção do valor 
material, mas com o foco para a construção de uma nova sociedade, incluindo as artes e a filosofia.

Essa relação entre trabalho e ensino ganha importante marco com o surgimento do ensino por complexos (BOLEIZ JÚNIOR, 2017; CUNHA; SILVA, 2016; LUCENA et al., 2011; SACHS; CORRÊA, 2020; SOARES DOS SANTOS; PALUDO, 2016). De acordo com o conteúdo descrito nos documentos pistrakianos, os complexos emergiram em Lepeshinskiy quando o Conselho Escolar considerou que cada disciplina deveria articular o interesse das crianças, que aparecem no processo da vida de trabalho deles, relacionando-os com alguns aspectos da fábrica. Isso seria feito através do ensino que instigasse os jovens; para tanto, colocavam-se uma série de pequenos problemas científicos.

Pistrak descreveu da seguinte maneira o surgimento dessa proposta:

A construção do programa, de acordo com esta exigência, levou por si à organização de cada disciplina em uma série de pequenos temas, que entraram no curso, mas que tocavam este ou aquele aspecto da fábrica. Cada um desses temas apresentou uma pequena tarefa científica, uma pequena pesquisa, de acordo com as possibilidades do estudante, para execução da qual ele deveria aprender a dominar o material, aplicar os métodos científicos à sua elaboração e anotar seus resultados. Tal método de trabalho deveria acostumar o estudante à autonomia, à autoatividade $^{(\mathrm{sic})}$. Ele mostrou ao estudante desde o próprio início o objetivo para o qual deve dirigir-se, um objetivo próximo aos seus interesses e, por isso, impulsionou-os para um trabalho criativo definitivo. É inteiramente irrelevante que os temas fossem diretamente ligados com um dado trabalho concreto na fábrica - aqui é suficiente (mas também necessário) que esta ligação, ainda que através de uma série de elos intermediários, seja percebida pela criança nos limites do seu horizonte, aberto para ela no trabalho da fábrica. (PISTRAK, 2009, p. 182 , grifos do autor)

No fragmento supra apresentado, nota-se que o trabalho é visto pelo pedagogo russo como uma ação criativa do ser humano, permitindo aos jovens desenvolver a autonomia e autogestão, através de uma organização sistemática do labor. Cunha e Silva (2016) destacaram que a categoria complexo de ensino é uma referência ao reconhecimento de que a realidade não é simples e que suas diversas partes se encontram interligadas num todo dialético, seguindo um ponto de vista coerente com a conotação filosófica crítica do marxismo. 
Soares dos Santos e Paludo (2016) inferiram que um ensino através do Sistema de Complexos é constituído por vários centros de interesse inter-relacionados. $\mathrm{Na}$ perspectiva pistrakiana, a escolha do tema de um complexo era guiada pelas metas educacionais traçadas no projeto pedagógico da escola. Por isso, aquilo que determina seu tema deve vir de um fenômeno de grande relevância e de alto valor social, enquanto mecanismo de construção do saber dos jovens sobre a realidade atual. Tal relevância deriva do caráter social do fenômeno e, não apenas, de sua adequação pedagógica, visto que se busca o estudo científico sobre a realidade (AMBONI; BEZERRA NETO; BEZERRA, 2013; QUARESMA, 2018).

Seguindo com o apanhado documental, o próprio pedagogo retratou, concretamente, a construção das propostas dos programas da comuna escolar de Lepeshinskiy: "[...] cada disciplina propunha, em ligação com o curso, uma série de temas, os quais eram trabalhados em grupo, ou por alguns estudantes (às vezes um)" (PISTRAK, 2009, p. 183).

Para exemplificar, Pistrak (2009, p. 183) relatou o que ocorria no campo das ciências da natureza, no qual um complexo foi elemento de destaque. Ao estudarem sobre o labor da oficina e de um fábrica de vestuário, os jovens faziam associação disso com o campo do estudo das substâncias químicas e das trocas de energia entre os fenômenos. De maneira mais direta, pode-se inferir que no programa de química foram planejados três temas básicos: “[...] alvejamento, processo de coloração e aquecimento. Ao estudo deles deve anteceder um curso teórico. (O tema 'aquecimento' relacionou exitosamente o trabalho da química e da física)" (PISTRAK, 2009, p. 183).

Apesar de um certo sucesso alcançado pela área de ciências da natureza na escolacomuna, Pistrak (2018, p. 159) afirma que outras experiências russas tiveram maior dificuldade em desenvolver as atividades de ensino por complexos: “[...] Física, Matemática e Ciências Naturais, que representam fielmente as disciplinas que são dadas por professores especialistas, têm dificuldade para alterar a noção habitual sobre a independência e o valor educativo de suas disciplinas".

Os complexos tinham como intuito gerar uma vinculação entre suas partes, seus subtemas, como os supracitados processos de coloração e aquecimento, unificadas pelas relações com o tema que lhe dão fundamento (reações físicas e químicas), articulados 
com o trabalho (oficina, fábrica, horta, etc.). O ensino por complexos organizava-se de maneira a ampliar paulatinamente a compreensão dos estudantes sobre do mundo que os cerca (BARROSO et al., 2020; GOLOVATY 2017a; 2017b).

Os temas curriculares na escola do trabalho socialista tinham como conceito articulador central o Complexo de Estudo. Assim, o labor é a base da vida social, portanto, ele deve estar no centro do estudo. Explicitando um excerto de autoria do pedagogo russo, consta que a criatividade advinda da subjetividade científica ou o trabalho do cientista, bem como o próprio ensino dos conhecimentos deste campo na antiga escola, tinham como objetivo puramente o conhecimento em si mesmo. Em oposição, na nova escola “[...] a ciência deve ser dada apenas como instrumento de compreensão e transformação da realidade, do ponto de vista das finalidades gerais da educação" (PISTRAK, 2018, p. 159).

A proposta do ensino pistrakiana era que natureza e sociedade, em conexão com o trabalho, se constituíssem em complexos a serem estudados pelos jovens da comuna escolar através dos complexos. Neles, os elementos da técnica e da tecnologia na Biologia, Física e Química ganham significados sociais, e não mais de maneira meramente contemplativa. A produção passa a ser “[...] a constante ligação entre as disciplinas científico-naturais e as ciências sociais (uma transição da técnica para a economia e viceversa) etc." (PISTRAK, 2018, p. 164).

Lucena et al. (2011) comentam que o colega de Pistrak responsável por articular e relatar as experiências do campo das ciências da natureza, um pedagogo tão entusiasta como ele, foi Robert M. Mikelson. Esse último foi professor de Ciências Naturais e de Economia Rural na escola-comuna Lepeshinskiy, e, posteriormente, tornou-se membro da Academia das Ciências Pedagógicas da Rússia e diretor do Instituto de Pesquisa Científica de Pedagogia de Latvia (atual República da Letônia).

No texto intitulado "Ciências Naturais", que consta como parte integrante da obra organizada por Pistrak (2009), Mikelson relata alguma de suas experiências pedagógicas na comuna escolar. Vários temas das ciências da natureza, através do estudo por complexos, são detalhados na obra. Por exemplo, narrando os acontecimentos do verão de 1923, o tema estudo da terra é destaque ao possibilitar aos estudantes o estudo de: 
1. Solos locais. 2. Cultura dos Campos locais. 3. Cultura de hortaliças locais. 4. Estufas. 5. Espécies de árvores locais. 6. Flores da região (mais comuns). 7. Plantas aquáticas. 8. O Bosque como comunidade. 9. Prados, balanços qualitativo e quantitativo. 10. Tipos locais de Currais domésticos. 11. Produtividade média de Cultura de Campo locais e formas de cultivo (alternância). (MIKELSON, 2009, p. 209)

O excerto acima descreve os subtemas ligados ao complexo de estudo da terra. Nota-se que o pedagogo da área de ciências da natureza elaborou seu curso elencando pontos fundamentais da propositura da chamada por Barroso et al. (2020) de pedagogia russa. Na passagem supra indicada, Mikelson (2009) traz a relação com a comunidade de entorno da escola como um elemento agregador ao ensino, partindo do princípio de que a escola faz parte da sociedade e não deve ser uma instituição segregada dela. Por isso, ele parece tratar como fundamental que as crianças moscovitas partam do mundo concreto que as cerca conhecendo, por exemplo, analisando em excursões as espécies de árvores locais, a flora comuns da região e seus solos típicos. Em seguida, após esse levantamento, o saber era ampliado e sistematizado dentro das atividades escolares da área de ciências naturais, dentro dos gabinetes de estudo, laboratórios, através de palestras e do estudo dos livros disponíveis (esse último era indicado para os alunos dos grupos mais velhos na comuna).

Outrossim, destaca-se na proposta pedagógica desenvolvida na comuna escolar, ligação do ensino e trabalho, no caso acima, com o labor no campo, exemplificado no trecho acima (cultura dos campos locais, cultura de hortaliças locais, estufas e a produtividade média do plantio). Nessa experiência educativa de ensino por complexos, buscava-se desenvolver um ensino coerente com o método dialético de interpretação da realidade). Tal sistema era para os pedagogos de Lepeshinskiy mais do que um método de ensino, era uma tentativa de organizar um programa escolar que incluísse a dimensão de estudo intimamente ligada ao trabalho técnico, a auto-organização dos educandos e ao trabalho social da escola (BOLEIZ JÚNIOR, 2017; VALLE; ARRIADA, 2014).

A proposta pedagógica era que, ao passo que os alunos fossem estabelecendo vínculos entre as várias dimensões da vida na comuna escolar, eles poderiam ter seus estudos desdobrados em ações, e estas últimas produziram a necessidade de novos estudos (BARROSO et al., 2020; QUARESMA, 2018; VALLE, 2012). Indo ao encontro desse 
ponto de vista, encontram-se elementos documentais que apoiam a perspectiva, como no excerto a seguir:

Nós procuramos distribuir as matérias dos programas pelos temas-tarefa, fundamentando-os metodologicamente. Dessa maneira, criaram-se cursos sistemáticos um tanto originais, os quais deram aos estudantes conhecimentos necessários mais profundos com o esclarecimento teórico deles, porque nós consideramos que, durante o período de acumulação do material concreto, aparece no estudante o desejo de compreendê-lo teoricamente e generalizar. (PISTRAK, 2009, p. 199)

Isso exposto denota a essência da proposta da escola-comuna e de sua organização curricular. Assim, é razoável analisar como Mikelson e Pistrak descrevem a materialização na prática escolar do ensino por complexos, dando foco aos fatos expostos na área de ciências da natureza. De início, pode-se evidenciar que na escolacomuna não havia salas de aula como na compreensão antiga dessa palavra, aquela da escola burguesa. O ensino sistemático, fora o ocorrido nas áreas externas (campo experimental, horta, oficina, fábrica, excursões etc.), acontece nos gabinetes ou laboratórios. "Os gabinetes são sete: física química matemática ciências naturais gabinete de arte Ciências Sociais e música literatura; há um clube junto a biblioteca e sala para educação física" (PISTRAK, 2009, p. 189). Assim, os grupos de alunos seguiam entre esses espaços, de maneira ordenada e divididos em horários específicos, realizando suas atividades sob a mediação dos pedagogos.

No ensino por complexos dentro da área de ciências da natureza se sugestionava com afinco o estudo dialético sobre o mundo material, como foco na pesquisa desenvolvida pelos grupos de alunos. Mikelson (2009, p. 386) afirma que a educação deveria “[...] infundir o método de pesquisa, ensinar a observar orientar-se independentemente no campo da natureza". O pedagogo admoestou que tal método de pesquisa não é um objetivo em si das aulas de ciências da natureza, mas destacou que era “[...] necessário colocar as bases deste método e preparar os alunos para a análise autônoma dos fenômenos sociais mais complexos" (MIKELSON, 2009, p. 386). A ciências da natureza deveriam desempenhar um papel extremamente importante na questão da formação da compreensão do mundo materialista dos alunos. 
A proposição dos pedagogos da escola moscovita, de base marxista, vai ao encontro de uma visão de ciência da natureza que caminha pela compreensão histórica e dialética de ser humano, de sociedade e de cultura, as quais são fundadas historicamente através da produção material da humanidade, e de sua relação dialética com o ambiente, o organismo e os fenômenos físicos, ao mesmo tempo em que estes também forjam aqueles (SHEEHAN, 1985). Dito isso, destaca-se que no campo do ensino de ciências da natureza existe uma verdadeira carência deste tipo de abordagem no Brasil, uma vez que a educação nesta área é dominada por filosofias não-dialéticas de ensino (FEITOSA; LEITE, 2014).

Uma pedagogia que leve em consideração essa perspectiva, como o ensino por complexos, deve ter compreensão de que seu princípio básico é a contradição que há na realidade material de seus educandos, pelo fato de ela possuir muitas faces. Essa contradição proporcionará um movimento do pensamento, uma reflexão que se findará na realidade concreta. Sobre esse tipo de pedagogia, Sachs e Corrêa (2020) afirmaram que os jovens de uma escola brasileira submetidos ao ensino por complexos possuem uma maior conexão com sua realidade. A obra pistrakiana, parece ser de grande valia para embasar o desenvolvimento de propostas similares.

Para atingir tais metas, o pedagogo da área de ciências da natureza da nova escola comunista possuía como tarefas básicas: “[...] preparar o terreno, acumular material [...] e generalizar este material numa compreensão do mundo materialista global, estabelecendo forte contato com a compreensão materialista-histórica" (MIKELSON, 2009, p. 387). Os materiais aos quais se referiu Mikelson, incluíam tanto os saberes quanto as ferramentas físicas, como livros, materiais de coleta para as aulas nos laboratórios ou gabinetes e aqueles ligados ao setor produtivo (horta, campo experimental, fábrica e oficina).

Com relação aos aspectos temporais da organização da área de ciências da natureza, a atuação dos complexos de ensino distribuía-se entre os seguintes temas: “[...] botânica, zoologia, anatomia, fisiologia humana e conversas sobre biologia geral - Ao todo são 10 horas para quatro grupos: no primeiro e segundo - 3 horas para cada um, e do [grupo] III e IV - 2 horas para cada um" (MIKELSON, 2009, p. 387). O autor afirma que existiam flutuações de tempo semanal na disciplina dentro da escola-comuna, variando 
ao longo das estações do ano, com maior dedicação no verão russo, a serviço do trabalho no campesinato escolar (plantação de vegetais, colheita, preparação de terreno etc.).

No que se refere aos métodos usados para o ensino dos complexos na escola Lepeshinskiy, os documentos analisados indicam que o método de pesquisa tinha lugar privilegiado (PISTRAK, 2009, 2015, 2018). Entretanto, também outros foram utilizados, segundo o relato do pedagogo da área de ciências, adaptando o ensino de acordo com o desenvolvimento dos níveis de complexidade inerentes a cada grupo de estudantes. $\mathrm{O}$ primeiro grupo, aquele composto por estudantes noviços, trabalha quase inteiramente pelo método de pesquisa, utilizando material laboratorial e excursões. No segundo e terceiro grupos utilizavam-se técnicas de ensino demonstrativo e ilustrativo. "Por este método trabalha-se aproximadamente a terceira parte do curso nos últimos dois grupos, quase a metade do curso trabalha-se pelo método de pesquisa, e a outra metade pelo método demonstrativo e ilustrativo" (MIKELSON, 2009, p. 388). E finalmente, no IV e derradeiro grupo de alunos era dada especial atenção para o estudo através da leitura de livros e outros materiais bibliográficos, sobretudo revistas e jornais.

Dentre os materiais mais utilizados para as aulas, o pedagogo da área indicava que deveria ter como requisito serem objetos ou espécimes simples e facilmente acessíveis à coleta por todos. Segundo o relato disponível em um dos documentos, as coleções compradas prontas "[...] servem muito menos para o trabalho. [...] Mais que tudo utilizamos no processo, material bruto de coleta" (MIKELSON, 2009, p. 389). A coleta desses materiais era feita pelos próprios estudantes e/ou pelos pedagogos da escola, através de excursões (aulas de campo) e de objetos arrecadados no setor produtivo.

Durante as atividades da disciplina, os educandos trabalhavam de maneira autônoma, sendo a tarefa primordial do pedagogo observar e indicar se o esboço e a descrição feitas pelos jovens estavam corretos. No final da aula, destacou Mikelson (2009, p. 394), “[...] faz-se uma verificação geral e a nota-se nomes especiais”. Tais nomes especiais, parece ser uma referência às definições científicas sobre materiais químicos, físicos e biológicos.

Fruto dessas atividades de pesquisa e coleta de material, Mikelson (2009) escreveu que dentro do subtema de botânica, a equipagem didática usada continha sementes preparadas de trigo, ervilha, girassol e cedro. Não era usada nos primeiros 
encontros didáticos nenhuma tabela ou modelo. Os estudantes recebiam a tarefa de examinar atentamente o material, desenhar, esboçar e descrever suas impressões em seus cadernos. Em seguida, passavam a examinar cuidadosamente a constituição interna dos espécimes e de novo esboçar e escrever. Exemplificando a partir dessa premissa: "Exatamente desta forma elaboram-se as questões: raízes, sua constituição, desenvolvimento e significado para a vida da planta, caule, folhas, flores e frutas e como questão especial a célula." (MIKELSON, 2009, p. 395).

A vida das plantas foi um dos temas abordados para os estudantes noviços, aqueles do grupo I. Mikelson (2009, p. 392) relatou que, quando era possível, os alunos iam a uma série de excursões ao ar livre nas imediações de Moscou. Nelas, o objetivo era estudar as "Árvores do nosso bosque". O método era voltado à pesquisa científica, no qual os jovens deveriam examinar quais árvores cresciam no bosque, caracterizar suas propriedades, descrever os espécimes, contabilizar quantas plantas havia de cada espécie biológica. Finalizava com a coleta de espécimes de folhas, as quais eram, posteriormente, analisadas nos gabinetes da escola.

Outros subtemas do complexo foram "Como as plantas preparam-se para o inverno", "Sementes, sua constituição e germinação" e "A significação das sementes para o homem" (MIKELSON, 2009, p. 393-4). O mesmo ocorria para os outros órgãos dos vegetais, isto é, raízes, caule, flores e frutos. O pedagogo de ciências destacou que o ensino abarcava não apenas as características biológicas e reprodutivas, mas se buscava uma relação da reprodução das plantas com o desenvolvimento agrícola. "Desta forma, prepara-se o terreno para a geografia econômica e economia política." (MIKELSON, 2009, p. 395). Aqui, novamente, encontram-se elementos que ligam o ensino com o trabalho educativo, corroborando as percepções de vários pesquisadores da literatura da pedagogia russa (AMBONI; BEZERRA NETO; BEZERRA, 2013; CUNHA; SILVA, 2016; GOLOVATY, 2017a, 2017b; PERGHER; FRIZZO, 2018; VALLE, 2012).

Mikelson (2009, p. 397) escreveu que o trabalho de pesquisa dos estudantes sobre os temas botânicos seguia esses temas e era conduzido autonomamente. $O$ trabalho das excursões e nos laboratórios era acompanhado pelo pedagogo e finalizado com palestras, dos seguintes temas: 
1. Nossos cereais cultivados. 2. Preparação do solo e rotação de plantio. 3. Nossa hortaliças. 4. Plantas que produzem fibra. 5. Prados. Preparação dos prados. Colheita de feno. 6. Madeira. Tratamento de madeira. Exportação de madeira. 7. Bosque como organização de árvores. 8. Como se protegem as plantas de seus inimigos. 9. Plantas aquáticas e suas especificidades. 10. Dependência das plantas do meio ambiente, etc. (MIKELSON, 2009, p. 397)

Outro tema ligado à área de ciências da natureza era o estudo zoológico, o qual incluía uma visão em ordem crescente de desenvolvimento, desde o estudo de organismos unicelulares, protozoários, até outros, como os “celenterados", "vermes", artrópodes e crustáceos (MIKELSON, 2009, p. 398). Ademais, havia o estudo através do trabalho com as classes de peixes, estudados através de observação externa, de seus movimentos, classificação e da parte interna (feita através da autópsia de espécimes). 0 mesmo tratamento era dado às classes aves e mamíferos. Em especial, no verão, quando os estudantes finalizavam seus trabalhos de forma empírica autônoma, analisando as seguintes temáticas:

1. Espécies locais de gado doméstico. 2. Espécies locais de aves domésticas. 3. Estações pecuárias e sua influência na economia Rural. 4. Quantidade de gado antes e depois de guerra no campo. Cálculo de gado em alguma aldeia. 5. Matadouro de Moscou e abastecimento de Moscou com carne. 6. Inimigos do campo e luta contra eles. 7. Inimigos do bosque. 8. Mamíferos locais silvestres e sua caça. (MIKELSON, 2009, p. 399)

Denota-se, a partir dos trechos expostos acima, a relação dos conteúdos abordados nos complexos com o setor produtivo, haja vista que a realidade laboral concreta é o mote gerador do princípio de ensino. Assim, tal abordagem considerava o trabalho em sua dimensão histórico-ontológica e como tal, indissociável da educação humana (SACHS; CORRÊA, 2020). Em concordância, retomando a biografia de Pistrak (2009, 2015, 2018), o importante para a proposta educativa era introduzir o trabalho como fundamento e objetivo do ensino na comuna escolar, e romper com a tradição da velha escola que pregava o ensino escolástico e desalinhado das necessidades reais da sociedade russa de seu tempo histórico. No que tange a esse pensamento, Cunha e Silva (2016) mostraram que o ensino por complexos também pode ser usado nos dias que 
correm no Brasil para o ensino de ciências da natureza, tanto no ensino escolar como no universitário.

No que diz respeito ao tema do estudo do corpo humano, Pistrak (2018, p. 178) indicou um caminho de ensino através do complexo "ser humano". Nele, pode-se "[...] analisar o ser humano apenas como uma criatura biológica e só, mas pode-se a partir do mesmo tema ir analisar, digamos, o trabalho humano socialmente necessário, colocando o problema do trabalho livre e do trabalho dependente". Desta feita, outros temas seriam contemplados, como, por exemplo, as formas sociais do trabalho, a luta contra a exploração, a revolta social. A alimentação humana pode ser estudo do ponto de vista da fisiologia, mas também pode ser colocado em ligação, digamos com os órgãos governamentais e da cooperação. Mais adiante, continua: “Abordando assim o complexo 'ser humano', vamos imediatamente tocar na relação existente entre esse tema e o que se segue depois dele no programa: 'A Revolução de Outubro'. Assim, esses dois complexos estão intimamente relacionados, "[...] como se um penetrasse no outro" (PISTRAK, 2018, p. 179).

O estudo sobre o corpo humano é mais detalhado no que tange ao curso do terceiro grupo escolar em Lepeshinskiy. Esclarecem que esse tema possui ligação com seu trabalho na fábrica e são estudados: "[...] anatomia, fisiologia humana, higiene e compreensão básica sobre doenças e funcionamento do nosso corpo como máquina" (MIKELSON, 2009, p. 399). Em adição ao estudo anatômico e fisiológico, também se estudavam questões ligadas à higiene humana. O objetivo desse tema era fornecer uma análise científica do movimento humano no labor produtivo.

$\mathrm{Na}$ comuna escolar eram proferidas palestras sobre o tema do corpo humano. Contudo, a maior parte da carga horária era dedicada ao trabalho na fábrica e no campo experimental de verão. Excursões e a observação sistemática do labor fabril eram métodos também usados. "Antes de iniciar os esclarecimentos teórico nas questões mencionadas, é proposto aos alunos conduzir na fábrica o trabalho com os temas indicados" (MIKELSON, 2009, p. 401).

Para a pedagogia russa era fundamental inculcar o espírito marxista de pesquisa sobre a realidade material da natureza e da sociedade, para que os jovens percepcionassem a realidade de forma dialética, como passo inicial para transformá-la. 
Era assim que se propunham os complexos da área de ciências da natureza e de seus subtemas. Assim, a escola única do trabalho devia se ligar ao contexto real de seus alunos, e não como algo apartado da realidade deles (BARROSO et al., 2020). Neste sentido, os excertos encontrados na presente pesquisa documental das obras de Pistrak (2009, 2015, 2018) e Mikelson (2009) trazem em sua práxis pedagógica elementos que permitem enquadrar tais ações nas categorias elementares da Pedagogia soviética, expressamente, atualidade, auto-organização, coletividade e trabalho. Esses resultados corroboram as pesquisas de vários autores, os quais evidenciaram que havia uma articulação entre essas categorias e a educação na nova escola do trabalho (BOLEIZ JÚNIOR, 2017; CONDE; COSTA, 2019; CUNHA; SILVA, 2016; GOLOVATY 2017a, 2017b; SOARES DOS SANTOS; PALUDO, 2016).

Finalmente, as questões de reprodução também tinham destaque na comuna escolar, "Todas as questões da assim chamada formação sexual devem receber fundamentos claramente científicos." (MIKELSON, 2009, p. 387). A partir desse excerto, pode-se inferir que os pedagogos da escola Lepeshinskiy encaravam o tema da reprodução dos seres vivos como elemento integrante do saber escolar. Com relação ao estudo da sexualidade humana, pode-se dizer que a educação sexual é um fenômeno da sociedade e encontra na escola um reforço institucional de suas bases sociais. A abordagem científica do saber ligado ao corpo humano, da reprodução e de sua sexualidade servem de elemento fundamental aos jovens para a compreensão desses fenômenos e de sua relação com a sociedade.

A respeito desse ponto, Nunes (2006) destacou que em uma visão ontológica da sexualidade humana encontram-se presentes elementos que vão além de aspectos subjetivos do ser; existem diversos fatores que devem ser abordados, como por exemplo, exigências de ordem social, ética e política. Assim, é possível pensar numa educação sexual mais abrangente.

Na comuna escolar aqui analisada, os documentos apontam que, para o primeiro grupo escolar, os temas da reprodução e sexualidade humana eram abordados cientificamente e socialmente, e até mesmo de maneira ligada ao saber filosóficoreligioso. A reprodução dos seres vivos se inicia pelo estudo do tema nas plantas, passando para a reprodução assexuada e sexuada na zoologia. Na medida em que se 
complexificam os grupos escolares, estudava-se o aparato sexual e reprodutivo dos animais e os órgãos sexuais humanos. "Aqui também conduzimos a conversa sobre as questões da vida sexual” (MIKELSON, 2009, p. 406).

Já no grupo escolar derradeiro, o grupo IV do $2^{\circ}$ Grau, tem-se o estudo das bactérias, com foco especial nas consideradas nocivas e, entre elas, "[...] as doenças venéreas" (MIKELSON, 2009, p. 406), abordadas tanto do ponto de vista biomédico como também social. Essa última abordagem, vai ao encontro de uma visão dialética do ensino do tema da sexualidade humana, fruto de uma totalidade advinda da filosofia marxista, conforme afirmou Nunes (2006). Isso porque, as evidências documentais indicam que, dentro do complexo de ensino do estudo do corpo humano, a sexualidade não era ensinada pelos pedagogos da comuna escolar de Lepeshinskiy de maneira meramente fisiológico-anatômica, e sim com uma visão totalizante, de modo a circunscrever o tema de modo amplo, como uma expressão biológica, social, histórica, econômica e filosófica.

\section{Considerações sobre a investigação}

A investigação apresentada permitiu, de maneira introdutória, identificar a organização, funcionamento e elementos curriculares constituintes do campo do ensino de ciências da natureza na escola moscovita de Lepeshinskiy. Ademais, os documentos analisados e a literatura levantada indicaram o uso de algumas metodologias para as atividades pedagógicas, como o uso da pesquisa empírica, experimentação, demonstrações, leitura de livros, excursões e palestras. Esses resultados podem trazer contribuições significativas para futuras investigações que visem aprofundar os estudos sobre os processos de ensino-aprendizagem pautados nos pressupostos da pedagogia russa.

Nesse processo, foi possível observar que os pedagogos da referida escola utilizavam o ensino por complexos, edificando uma teoria pedagógica com base na articulação entre trabalho e educação. Tal articulação tinha base dos momentos interativos entre os grupos de estudantes e os educadores, de modo que contribuiu para 
a assimilação não apenas de conhecimentos científicos, mas também sobre o saber social, cultural, filosófico e político de seus educandos.

Sobremaneira, os dados da presente pesquisa evidenciam a proposta de uma escola do trabalho, emergida no movimento revolucionário na Rússia de 1917 de base marxista, que visava o contexto no qual o aluno estava inserido e a sua responsabilidade na transformação da sociedade, sendo o objetivo principal educar para essa incumbência.

Nesse sentido, sinteticamente, pode-se inferir algumas conclusões tiradas por Pistrak e Mikelson sobre o trabalho na comuna escolar: a natureza da educação na escola única do trabalho, o papel cultural da nova escola e as relações entre as ciências e o trabalho.

Outrossim, levando-se em consideração o contexto histórico atual, advoga-se que os métodos empregados na escola moscovita para o ensino de ciências da natureza, servem como inspiração para a construção de propostas educativas hodiernas, as quais pensem na educação dos jovens de maneira histórica e crítica. Em adição, enfatiza-se a necessidade do desenvolvimento de novas investigações para o aprofundamento das concepções e práticas ligadas ao ensino de ciências no contexto da Rússia revolucionária.

\section{Referências}

AMBONI, Vanderlei; BEZERRA NETO, Luiz; BEZERRA, Maria Cristina dos Santos. Trabalho e educação na construção da Rússia socialista. Revista HISTEDBR On-Line, Campinas, v. 13, n. 51, p. 266-278, 2013. Disponível em: https://doi.org/10.20396/rho.v13i51.8640277.

Acesso em: 18 abr. 2020 
BARROSO, Maria Cleide da Silva; PEREIRA, Rafaela Fernandes; SANTOS FILHO, Antônio de Pádua Arruda dos; SANTOS, Murilo Rodrigues dos; MARTINS, Paulo Ícaro; HOLANDA, Francisca Helena de Oliveira. Moisey Mikhaylovich Pistrak: pedagogia russa, educação e revolução. Research, Society and Development, Itabira, v. 9, n. 5, p. e170952608, apr. 2020. DOI: http://dx.doi.org/10.33448/rsd-v9i5.2608. Disponível em: https://rsd.unifei.edu.br/index.php/rsd/article/view/2608. Acesso em: 18 abr. 2020.

BOGDAN, Robert C.; BIKLEN, Sari Knopp. Investigação qualitativa em educação: uma introdução à teoria e aos métodos. Portugal: Porto Editora, 1994.

BOLEIZ JÚNIOR, Flávio. A pedagogia social de Pistrak e a formação do homem novo. Journal of Social Pedagogy, [S.I.], v. 3, n. 1, p. 1-15, maio 2017. Disponível em: http://www.revistadepedagogiasocial.uff.br/index.php/revista/article/view/9. Acesso em: 18 abr. 2020.

CONDE, Soraya Franzoni; COSTA, Maicon Jackson Costa. Contribuições da pedagogia socialista para a educação da infância no Movimento dos Trabalhadores Rurais Sem Terra. Perspectiva, Florianópolis, v. 37, n. 4, p. 887-903, 2019. Disponível em: https://doi.org/10.5007/2175-795X.2019.e54987. Acesso em: 18 abr. 2020.

CRESWELL, John W. Projeto de pesquisa: métodos qualitativo, quantitativo e misto. 3. ed. Porto Alegre: Artmed, 2010.

CUNHA, Maria Bernadete de Melo; SILVA, José Luis de Paula Barros. Complexos temáticos na formação de professores do campo. Educ. rev., Curitiba, n. 61, p. 171-188, 2016. DOI: https://doi.org/10.1590/0104-4060.45967. Disponível em: http://www.scielo.br/scielo.php?script=sci_arttext\&pid=S010440602016000300171\&lng=en\&nrm=iso. Acesso em: 18 abr. 2020.

FEITOSA, Raphael Alves; LEITE, Raquel Crosara M. Contribuições da filosofia marxiana para o ensino de biologia. Revista da SBEnBio, Rio de Janeiro, v. 7, p. 6265-6277, 2014.

GOLOVATY, Ricardo V. A escola do trabalho de Moisey Pistrak (1918-1929): crítica da educação politécnica bolchevique. Enfrentamento, Goiânia, ano 12, n. 22, p. 79-97, 2017 a. Disponível em: https://redelp.net/revistas/index.php/enf/article/view/1016. Acesso em: 18 abr. 2020.

GOLOVATY, Ricardo V. A pedagogia socialista de Moisey Pistrak no centenário da revolução russa: contribuição pelo olhar da história e da sociologia da educação. História e Cultura, Franca, v. 6, n. 1, p. 213-240, mar. 2017b. Disponível em: http://dx.doi.org/10.18223/hiscult.v6i1.1981. Acesso em: 18 abr. 2020.

LOPES, Adriano Jorge Torres. Contribuições marxistas acerca da evolução biológica dos primatas como condição para o surgimento do ser social: primeiras aproximações. In: SILVA, Antonio Nascimento da; FREITAS, Maria Cleidiana Cavalcante; PAIVA, Isadora Barreto (org.). Marxismo, ciência e sertão: coletâneas de ensaios críticos. Fortaleza: EdUECE, 2018, p. 73-94. E-book. Disponível em: 
http://www.uece.br/eduece/dmdocuments/Marxismo\%20Ciencia\%20e\%20\%20Sertao\%20\%20EBOOK_12_03_2018.pdf. Acesso em: 18 abr. 2020.

LUCENA, Carlos; FRANÇA, Robson Luiz de; PREVITALI, Fabiane Santana; LIMA, Antônio Bosco de; OMENA, Adriana. Pistrak e Marx: os fundamentos da educação russa. Revista HISTEDBR On-Line, Campinas, v. 11, n. 41e, p. 271-282, 2011. Disponível em: https://doi.org/10.20396/rho.v11i41e.8639909. Acesso em: 18 abr. 2020.

MIKELSON, Robert M. Ciências Naturais. In: PISTRAK, Moisey M. (ed.). A escola-comuna. São Paulo: Expressão Popular, 2009. p. 385-408.

NUNES, César Aparecido. Dialética da sexualidade e educação sexual no Brasil. Revista linhas, Florianópolis, v. 7, n. 1, p.1-16, 2006. Disponível em:

http://www.periodicos.udesc.br/index.php/linhas/article/view/1329. Acesso em: 18 apr. 2020.

PERGHER, Eduardo; FRIZZO, Giovanni. Trabalho como princípio educativo: debate a partir de Gramsci e Pistrak. Revista Trabalho Necessário, [S.I.], v. 8, n. 10, 2018. DOI: https://doi.org/10.22409/tn.8i10.p6106. Disponível em: https://periodicos.uff.br/trabalhonecessario/article/view/6106. Acesso em: 18 abr. 2020.

PISTRAK, Moisey Mikhailovich (org.). A escola-comuna. São Paulo: Expressão Popular, 2009.

PISTRAK, Moisey Mikhailovich. Ensaios sobre a escola politécnica. São Paulo: Expressão Popular, 2015.

PISTRAK, Moisey Mikhailovich. Fundamentos da escola do trabalho. São Paulo: Expressão Popular, 2018.

QUARESMA, Adilene Gonçalves. trabalho e educação na perspectiva socialista: a experiência de Pistrak na escola comuna. Germinal: Marxismo e Educação em Debate, Salvador, v. 10, n. 2, p. 12-25, set. 2018. DOI: http://dx.doi.org/10.9771/gmed.v10i2.24443. Disponível em: https://portalseer.ufba.br/index.php/revistagerminal/article/view/24443. Acesso em: 18 abr. 2020.

SACHS, Línlya; CORRÊA, Larissa Geovana. Limites e possibilidades no planejamento e desenvolvimento de atividades com complexos de estudo na Educação do Campo. Educação Matemática Pesquisa: Revista do Programa de Estudos Pós-Graduados em Educação Matemática, São Paulo, v. 22, n. 1, p. 95-119, 2020. Disponível em: https://revistas.pucsp.br/emp/article/view/46099. Acesso em: 18 abr.

SHEEHAN, Helena. Marxism and the philosophy of science: a critical history. Amherst: NY Humanity Books, 1985.

SOARES DOS SANTOS, Franciele; PALUDO, Conceição. A atualidade das contribuições de Moisey M. Pistrak e Viktor N. Shulgin para a pedagogia do Movimento dos Trabalhadores Sem Terra. Perspectiva, Florianópolis, v. 33, n. 3, p. 1163-1183, abr. 2016. DOI: 
https://doi.org/10.5007/2175-795X.2015V33n3p1163. Disponível em:

https://periodicos.ufsc.br/index.php/perspectiva/article/view/33573. Acesso em: 18 abr. 2020.

VALLE, Hardalla Santos do. A história de dois educadores socialistas: alguns apontamentos sobre as experiências de Makarenko e Pistrak. Revista Didática Sistêmica, [S.I.], v. 14, n. 1, p. 15-28, 2012. Disponível em:

https://periodicos.furg.br/redsis/article/view/2518. Acesso em: 18 abr. 2020.

VALLE, Hardalla Santos do; ARRIADA, Eduardo. Makarenko e Pistrak: uma análise da pedagogia social do trabalho. Revista Portuguesa de Pedagogia, Coimbra, n. 46-1, p. 109125, 2014. DOI: https://doi.org/10.14195/1647-8614_46-1\%25x. Disponível em:

https://impactum-journals.uc.pt/rppedagogia/article/view/1786. Acesso em: 18 abr. 2020.

Recebido em: 04/05/2020

Revisões requeridas em: 12/12/2020

Aprovado em: 15/02/2021

Universidade do Estado de Santa Catarina - UDESC

Programa de Pós-Graduação em Educação - PPGE

Revista Linhas

Volume 22 - Número 48 - Ano 2021

revistalinhas@gmail.com 